\title{
Systematic review and meta-analysis of the efficacy of tension-free vaginal tape on pelvic organ prolapse complicated by stress urinary incontinence
}

\author{
Peng $\mathrm{He}^{1,2}$, Jianhua Zou ${ }^{1,2}$, Baisheng Gong ${ }^{1,2}$, Mingxing Qiu ${ }^{1,2}$, Lijun $\mathrm{Li}^{1,2}$ \\ ${ }^{1}$ Department of Urology, Sichuan Provincial People's Hospital, University of Electronic Science and Technology of China, Chengdu, China; \\ ${ }^{2}$ Chinese Academy of Sciences Sichuan Translational Medicine Research Hospital, Chengdu, China \\ Contributions: (I) Conception and design: P He, L Li; (II) Administrative support: J Zou; (III) Provision of study materials or patients: P He, J Zou, B \\ Gong, M Qiu; (IV) Collection and assembly of data: All authors; (V) Data analysis and interpretation: P He, M Qiu, L Li; (VI) Manuscript writing: \\ All authors; (VII) Final approval of manuscript: All authors. \\ Correspondence to: Lijun Li. Department of Urology, Sichuan Provincial People's Hospital, University of Electronic Science and Technology of China, \\ 32 West Section 2, First Ring Road, Qingyang District, Chengdu 610072, China. Email: lilijun897@163.com.
}

Background: Patients with pelvic organ prolapse combined with stress urinary incontinence (SUI) require pelvic floor repair and surgical treatment; however, there is currently no systematic evaluation of the treatment effect.

Methods: PubMed, Medline, Embase, Elsevier, The Cochrane Library, Web of science, and other databases were searched for randomized controlled trials (RCTs) published between January 2000 and December 2020 regarding tension-free vaginal tape (TVT) treatment of pelvic organ prolapse combined with SUI. Quality evaluation of the articles included in this study was conducted in accordance with the Cochrane Work Manual (5.3), and RevMan 5.3 software was used to conduct meta-analysis of the data extracted from literature meeting the requirements.

Results: A total of 10 articles were included, involving a total of 1,361 subjects, including 553 in the control group (a different surgical treatment) and 808 in the observation group (single TVT or TVT combined with pelvic floor repair). The bias evaluation results showed that all of the included literature was rated as level $\mathrm{B}$, so there was no need for sensitivity analysis. The meta-analysis showed that the combined effect size of the clinical cure rate was \{odds ratio (OR) [95\% confidence interval (CI)]: $3.82(1.39,10.52) ; \mathrm{Z}=2.59, \mathrm{P}=0.010$ \}, and the combined effect size of the clinical complication rate was [risk difference (RD) (95\% CI): -0.09 $(-0.16,-0.02) ; \mathrm{Z}=2.38 ; \mathrm{P}=0.02]$. The results showed that the clinical cure rate of the observation group was significantly higher than that of the control group, while the clinical complication rate was significantly lower than that of the control group $(\mathrm{P}<0.05)$.

Discussion: TVT surgery or TVT combined with pelvic floor repair surgery can significantly improve the cure rate of patients with pelvic organ prolapse combined with SUI, and reduce the incidence of postoperative complications. Therefore, TVT is a suitable surgical method for the treatment of patients with pelvic organ prolapse combined with SUI.

Keywords: Pelvic organ prolapse; stress urinary incontinence (SUI); tension-free vaginal tape surgery (TVT surgery); meta-analysis

Submitted Oct 27, 2021. Accepted for publication Dec 14, 2021.

doi: 10.21037/apm-21-3385

View this article at: https://dx.doi.org/10.21037/apm-21-3385 


\section{Introduction}

Stress urinary incontinence (SUI) is a common disease in middle-aged and elderly women, especially obese women who have given birth (1). Current studies have shown that the onset factors of SUI include age, changes in hormone levels, and increased body mass index, and are closely related to the number of deliveries, chronic pelvic pain, and pelvic organ prolapse (2). SUI mainly arises due to disorder of the bladder neck and its supporting system, dysfunction of urethral sphincter, dysfunction of the related nervous system, and the disorder of the urethral mucosalsealing function (3). Clinically, SUI is mainly divided into anatomical and urethral sphincter dysfunction types. Mild SUI can be treated with non-surgical methods, such as medication, pelvic floor muscle exercises, and biofeedback therapy. Surgical treatment is performed in cases of treatment failure (4). The surgical methods used for SUI include Burch surgery, tension-free vaginal tape (TVT), TVT through obturator (TVT-O), and transobturator tape (TOT) (5). TVT is a new surgical method for the treatment of tension urinary incontinence, which was proposed by Swedish scientist Ulmsten in 1996. In TVT surgery, a sling is passed through a small incision in the vagina and wraps around the middle of the urethra without tension. The operation is simple, the trauma is small, the complications are few, and the patient recovers quickly after the operation.

The incidence of pelvic organ prolapse has been found to increase with age, and is approximately $75 \%$ in women aged 50-59 (6). Clinically, the treatment methods for pelvic organ prolapse are divided into surgical and non-surgical treatments, of which the surgical treatment is mainly adopted (7). The common surgical treatments of pelvic organ prolapse include repair of the anterior and posterior vaginal wall, posterior vaginal sling, and uterine (vaginal vault) sacral sling (8).

Studies have shown that pelvic organ prolapse is closely associated with SUI $(9,10)$. Clinical trials have confirmed that women with SUI are often accompanied by mild or moderate cystocele (11), indicating that both pelvic organ prolapse and SUI belong to pelvic floor dysfunction. Furthermore, it has also been found that patients with pelvic floor dysfunction are often accompanied by SUI after pelvic floor repair treatment. Currently, anti-incontinence surgery is required (12).

At present, the effect of pelvic floor repair and antiSUI surgery on pelvic organ prolapse combined with SUI remains unclear, and large-scale randomized controlled trials (RCTs) on this topic are lacking. In this study, a metaanalysis was performed to explore the effect of pelvic floor repair and TVT surgery on pelvic organ prolapse and SUI, and analyzed the safety and effectiveness of surgical treatment, with the aim of providing a reference for the treatment of pelvic organ prolapse combined with SUI. We present the following article in accordance with the PRISMA reporting checklist (available at https://dx.doi. org/10.21037/apm-21-3385).

\section{Methods}

\section{Literature inclusion and exclusion criteria}

The inclusion criteria were as follows: (I) patients diagnosed with pelvic organ prolapse combined with SUI; (II) patients aged over 18 years old; (III) RCTs, quasi-RCTs, or clinical observation studies; (IV) the surgical intervention method is TVT or TVT combined with other surgical treatments; and $(V)$ studies involving a follow-up time of more than 6 months.

The exclusion criteria were as follows: (I) studies lacking a control group; (II) patients without SUI or pelvic organ prolapse; (III) studies with too many patient withdrawals; (IV) repeatedly published studies; (V) studies involving a sample size of less than 30 cases; (VI) clinical trials published in English; and (VII) studies involving patients that had taken drugs or accepted other surgical treatments have before surgery.

\section{Literature retrieval}

The PubMed, Medline, Embase, Elsevier, The Cochrane Library, and Web of science databases were searched for RCTs published from January 2000 to December 2020 using the following search terms: "stress urinary incontinence", "pelvic organ prolapse", "surgery", and "operative".

\section{Literature selection and quality evaluation}

Two experts independently screened the literature and conducted quality evaluation, and any inconsistencies were resolved by discussions or inviting another expert for arbitration.

The quality of the included studies was evaluated according to the Cochrane Work Manual (5.3). The evaluation criteria were as follows: (I) whether the random 
allocation method was described; (II) whether allocation concealment was adopted; (III) whether a blinding method as used; (IV) whether the outcome indicators were complete; and $(\mathrm{V})$ whether there were subjects lost to follow-up.

Studies meeting the above criteria were considered "low risk" and rated as A level. Studies that did not meet one of these criteria were considered "unclear risk" and rated as B level, while studies that did not meet more than one of these criteria were considered "high risk" and rated as C level.

\section{Data extraction}

The following information was collated from the included studies: basic document information (first author, year of publication, trial group, and sample size); and basic information of the study, which included baseline data (age, operation method, and operation time), operation treatment effect evaluation indexes (cure rate, postoperative complication rate (postoperative urinary dysfunction, infection, hematoma formation, and chronic pain), intervention methods, follow-up time, and outcome indicators.

\section{Statistical analysis}

The experimental data was processed by Statistical Product and Service Solutions 19.0 (SPSS, IBM Corporation, America). The quality of the included articles was evaluated according to the Cochrane Reviewer's Handbook. RevMan 5.3 software was used for meta-analysis. Binary variables were described by relative risk (RR), odds ratio (OR), or risk difference (RD); while continuous variables were described by weighted mean difference (WMD) or standard mean difference (SMD). The hypothesis test was performed to analyze whether there were statistically significant differences, the $Z$ and $P$ values in the forest map were factored in, and each effect size was represented by a $95 \%$ confidence interval (CI).

The chi-square test was used for the heterogeneity analysis, and the significance level of the test was $\alpha=0.05$, $\mathrm{P}<0.05$. The $\mathrm{I}^{2}$ statistic was used for quantitative evaluation of heterogeneity; $\mathrm{I}^{2}<25 \%$ was considered low heterogeneity, $25-50 \%$ was considered moderate heterogeneity, and $>50 \%$ was considered high heterogeneity. When $\mathrm{I}^{2}<50 \%$, the fixed effects model (FEM) was used; otherwise, the random effects model (REM) was used for analysis.

Sensitivity analysis is an effective method to ensure the stability and reliability of meta-analysis results. Commonly used methods of sensitivity analysis include: (I) the same data is analyzed using different models, and then the sensitivity analysis is performed by comparing the combined effect size and interval differences; and (II) abnormal results are excluded first (such as low quality, too small/too large sample size studies) and then meta-analysis is performed to compare the changes of the results before and after the elimination.

The forest map was then constructed to display the combined effect size, and the funnel chart displayed the heterogeneity results. $\mathrm{P}<0.05$ was the threshold for significance.

\section{Results}

\section{Literature retrieval results}

Initially, 4,755 documents were identified. Next, duplicate publications and unqualified documents were eliminated, leaving 3,514 articles. Thereafter, 3,309 were removed after reading the titles and abstracts. The 205 remaining articles were subsequently screened according to the inclusion/ exclusion criteria, and only 19 studies met the criteria. After reading these documents carefully, it was found that five documents did not list the cure rate in detail, and four documents did not compare the efficacy of TVT. Therefore, a total of 10 studies were finally included in the meta-analysis, as shown in Figure 1.

\section{Characteristics of the included literature}

The 10 articles included in the study involved a total of 1,361 subjects, including 553 in the control group and 808 in the observation group. All patients received surgical treatment, and the postoperative follow-up time was 6-70 months (some subjects were lost to follow-up). The basic information of the 10 articles is shown in Table 1 .

\section{Analysis of the source bias of the included literature}

The bias risk of the 10 documents was assessed according to the "12-item sources of risk of bias" developed by the Cochrane Collaborative Organization. As shown in Figures 2,3, each document described the random sequence generation (selection bias) and allocation concealment (selection bias), indicating a "low risk"; one article did not mention the blinding method, indicating an "unclear risk"; 


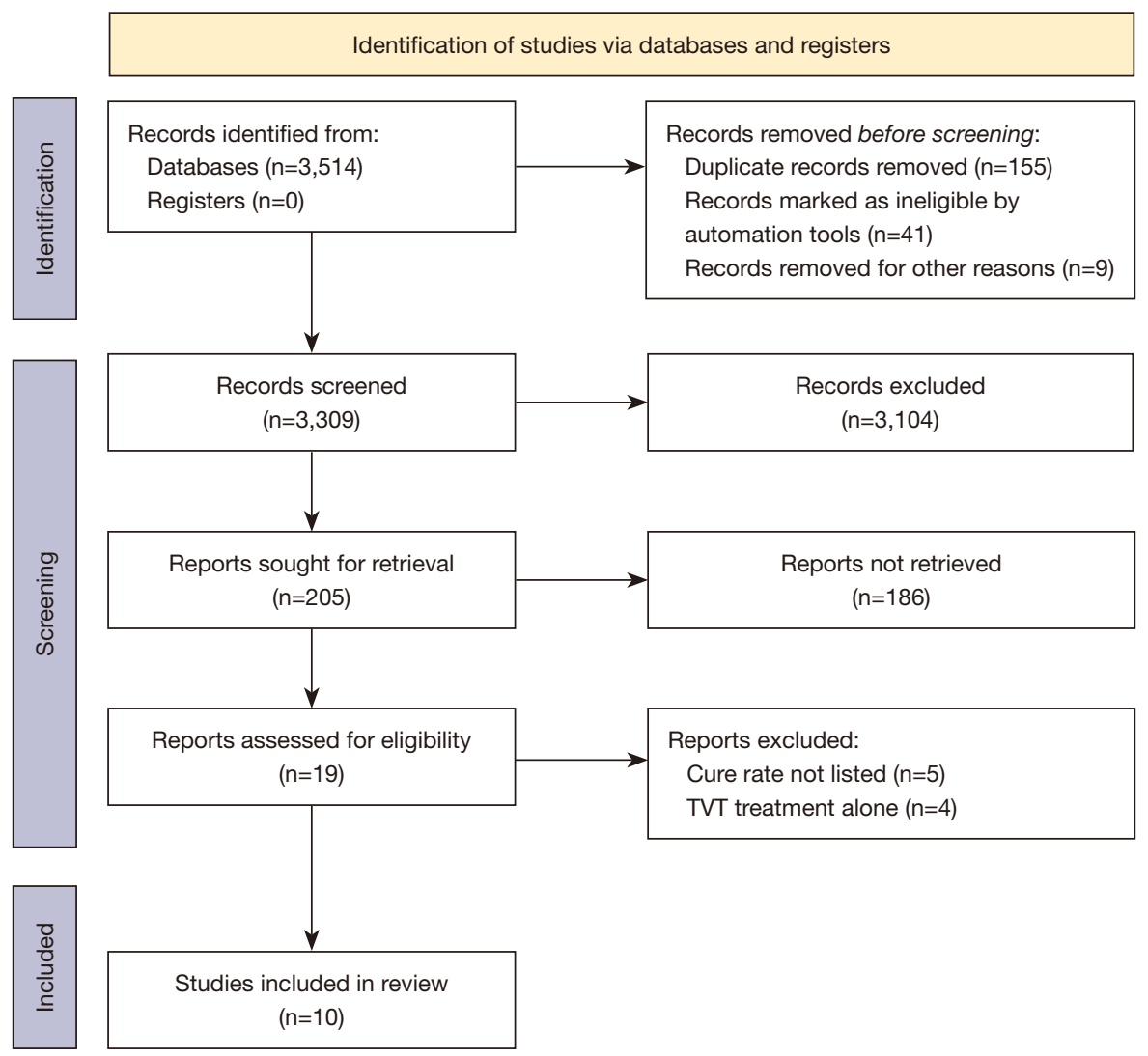

Figure 1 Literature retrieval flow chart.

Table 1 Basic characteristics of the included articles

\begin{tabular}{|c|c|c|c|c|}
\hline First author & $\begin{array}{c}\text { Year of } \\
\text { publication }\end{array}$ & $\begin{array}{l}\text { Sample } \\
\text { size }\end{array}$ & Surgical method in the control group & Surgical method in the observation group \\
\hline Borstad (13) & 2010 & 181 & Prolapse repair alone & Prolapse repair combined with TVT \\
\hline Costantini (15) & 2007 & 66 & Prolapse repair alone & Prolapse repair combined with TVT \\
\hline Costantini (16) & 2008 & 47 & Prolapse repair alone & Prolapse repair combined with TVT \\
\hline Meschia (18) & 2006 & 179 & IVS alone & TVT alone \\
\hline Montera (19) & 2018 & 80 & Prolapse repair alone & Prolapse repair combined with TVT \\
\hline de Tayrac (20) & 2004 & 29 & Prolapse repair alone & Prolapse repair combined with TVT \\
\hline
\end{tabular}

TVT, tension-free vaginal tape; IVS, intravaginal slingplasty. 


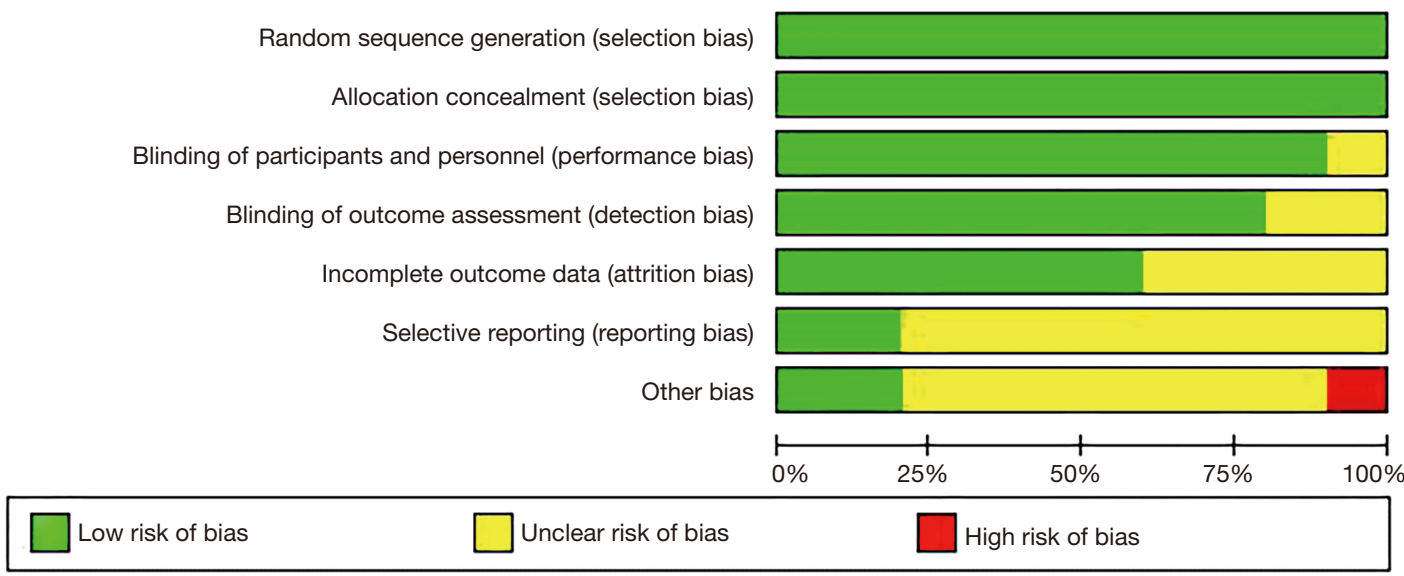

Figure 2 Bar chart showing the bias risk assessment results of the included literature.

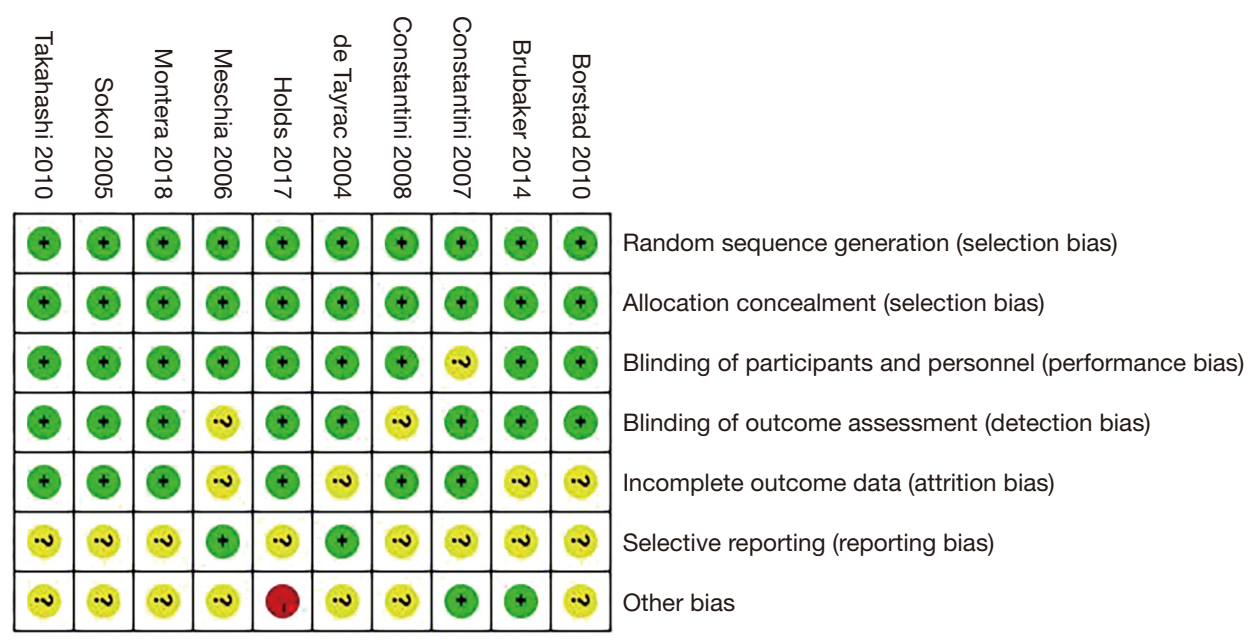

Figure 3 Risk assessment results of the included literature.

two studies did not mention the use of a blinding method in the outcome assessment, indicating an "unclear risk"; three documents had incomplete outcome data, indicating an "unclear risk"; eight documents were selective reports, indicating an "unclear risk"; seven documents had other biases, indicating an "unclear risk", and one article was "high risk". In summary, all 10 included articles were rated as level $\mathrm{B}$, so sensitivity analysis was not required.

\section{Meta-analysis results}

\section{Clinical cure rate}

As shown in Figure 4, the heterogeneity of the clinical cure rate was analyzed first, and the results showed that there was a high degree of heterogeneity $\left(\mathrm{I}^{2}=84 \%\right.$; $\left.\mathrm{P}<0.00001\right)$. Therefore, the REM was used for analysis. The combined effect size results were OR (95\% CI): $3.82(1.39,10.52)$, and the statistical structure was $Z=2.59, P=0.010$. Hence, the clinical cure rate of the observation group was significantly higher than that of the control group $(\mathrm{P}<0.05)$.

\section{Complication rate}

Figure 5 shows the complication rate (postoperative urinary dysfunction, infection, hematoma formation, chronic pain) after treatment. The results indicated a high degree of heterogeneity $\left(\mathrm{I}^{2}=70 \% ; \mathrm{P}=0.003\right)$, so the REM was used for 


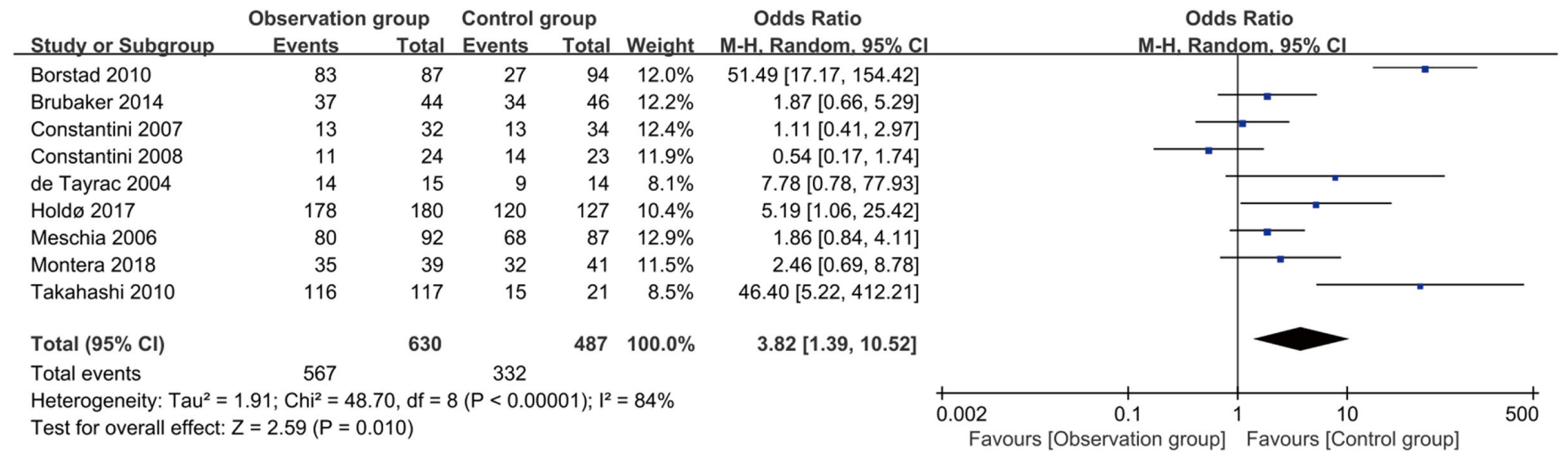

Figure 4 Forest plot comparing the clinical cure rates. CI, confidence interval.

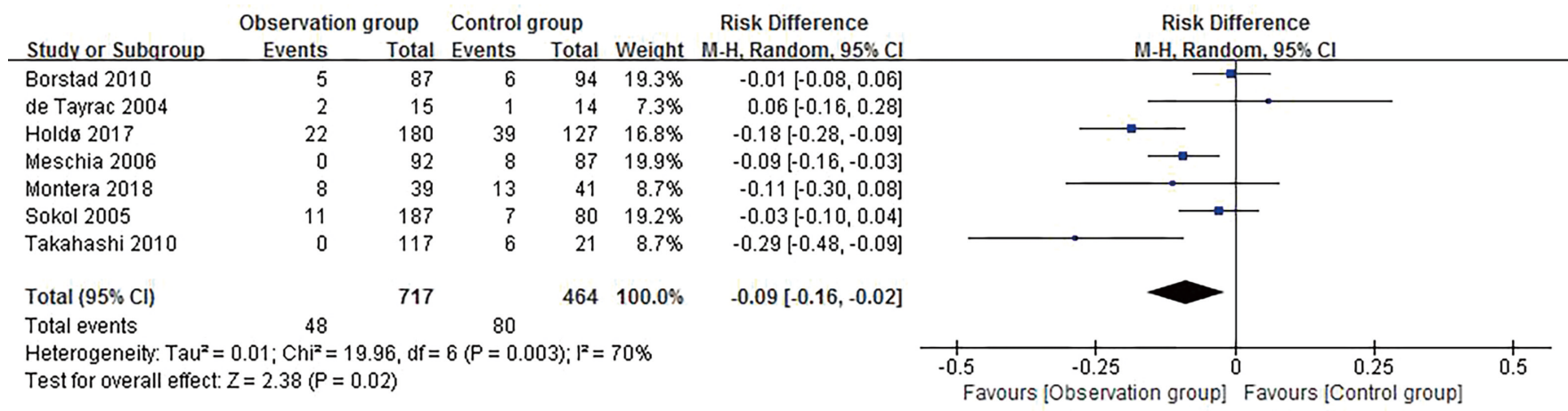

Figure 5 Forest plot comparing the clinical complication rate. CI, confidence interval.

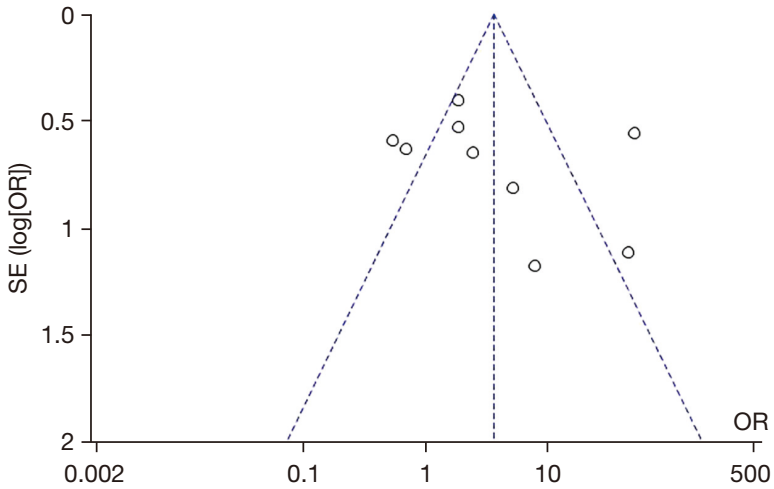

Figure 6 The inverted funnel chart of the clinical cure rate. SE, standard error; OR, odds ratio.

statistical analysis. The combined effect size results were RD (95\% CI): $-0.09(-0.16,-0.02)$, and the statistical structure was $\mathrm{Z}=2.38, \mathrm{P}=0.02$. Hence, the clinical complication rate after treatment in the observation group was significantly

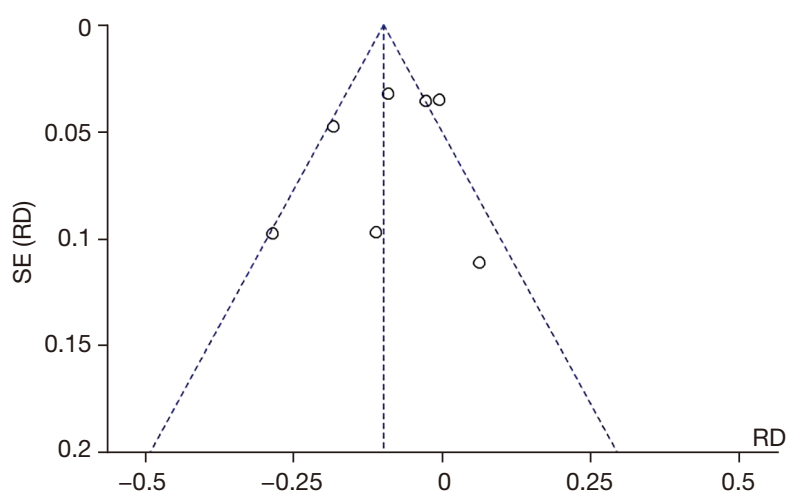

Figure 7 The inverted funnel chart of the clinical complication rate. SE, standard error; $\mathrm{RD}$, risk difference.

lower than that in the control group $(\mathrm{P}<0.05)$.

Publication bias

Figures 6,7 display the publication bias of the clinical 
cure rate and complication rate. It was noted that both of the inverted funnel charts of the clinical cure rate and complication rate were symmetrical, and almost all of the included studies fell within it. In terms of the clinical cure rate, only four studies did not fall into the inverted funnel chart, and only one study did not fall into the inverted funnel chart for the complication rate. All of the studies of the clinical cure rate and complication rate were close to the central axis, indicating low publication bias.

\section{Discussion}

At present, a large number of studies have demonstrated that pelvic organ prolapse is closely related to SUI (23). Moreover, pelvic organ prolapse and SUI have similar environmental, genetic, and risk factors (such as advanced age, obesity, multiple births, and constipation). Given that these two conditions have similar pathophysiological mechanisms of pelvic floor dysfunction, combined with the anatomical structure of the female pelvic floor, it is possible to use the same surgical method to perform pelvic floor repair and anti-SUI treatment at the same time (24).

TVT can treat patients with pelvic organ prolapse combined with SUI while repairing pelvic floor. Studies have confirmed that TVT surgery can significantly improve the clinical cure rate of patients with pelvic organ prolapse and SUI (25). In addition, studies have also shown that TVT surgery has high effectiveness and safety in the treatment of SUI after long-term follow-up (26). Bakas et al. confirmed that after 17 years of follow-up of female patients with SUI treated by TVT surgery, the subjective cure rate of TVT therapy was $78.6 \%$, the objective cure rate was $83.9 \%$, and the failure rate was $12.5 \%$ (27). However, studies have also shown that different TVT surgeries have different effects in the treatment of SUI (28). Song et al. confirmed through meta-analysis that TVT-O surgery had a significantly better objective cure rate and subjective cure rate for patients with SUI at 12 months compared with TVTsecure (TVT-S) surgery (29). Rodrigues et al. compared the effects of TVT, TVT-S, and TVT-O in the treatment of SUI, and the subjective cure rates after 3 years of followup were $88.5 \%, 78.4 \%$, and $88.5 \%$, respectively (30). Compared with TOT, TVT and TVT-O surgical methods have the advantages of high cure rate, shorter operation time, less surgical trauma and longer duration of curative effect. TVT-O surgery may increase the risk of vaginal injury, and there are risks of complications such as obturator hematoma, abscess formation, and vaginal sling erosion after surgery. Taken together, TVT treatment can significantly improve the clinical symptoms of patients with SUI, and the cure rate is high.

This article explored the clinical cure and complication rates of TVT surgery for female patients with pelvic organ prolapse combined with SUI through meta-analysis. The results showed that compared with pelvic organ prolapse repair surgery alone, pelvic floor reconstruction, and other surgical treatments, after TVT surgery or TVT combined with pelvic organ prolapse repair or pelvic floor reconstruction, the combined effect sizes of the clinical cure and complication rates were [OR (95\% CI): $3.82(1.39$, 10.52); $\mathrm{Z}=2.59 ; \mathrm{P}=0.010]$ and $[\mathrm{RD}$ (95\% CI): -0.09 (-0.16, -0.02); $\mathrm{Z}=2.38 ; \mathrm{P}=0.02$ ], respectively. Hence, the clinical cure and complication rates of patients after TVT surgery or TVT combined with pelvic organ prolapse repair or pelvic floor reconstruction are significantly improved. It can be concluded that TVT surgery can be used in the treatment of female patients with pelvic organ prolapse combined with SUI; it can significantly improve the clinical cure rate of patients and has a lower complication rate, and is thus worthy of clinical promotion.

However, this study has certain limitations that should be noted. Firstly, the number of included articles in this meta-analysis was small; only 10 studies were included to analyze the effect of TVT surgery in the treatment of female patients with pelvic organ prolapse combined with SUI. Additionally, this article unifies TVT, TVT-S, and TVT-O surgery as TVT surgery, and more research needs to be conducted in follow-up studies to analyze the differences between the treatment effects of the various TVT treatments. Furthermore, the individual studies included in this analysis exhibited large heterogeneity, and subsequent subgroup analysis is required to eliminate the influencing factors in the study to reduce the heterogeneity. Moreover, there were too few indicators for evaluating the treatment effect; only two indexes (cure rate and complication rate) were analyzed in this study. Therefore, the number of indexes needs to be expanded in follow-up research to analyze the clinical effect of TVT surgery in the treatment of pelvic organ prolapse combined with SUI in female patients.

\section{Conclusions}

This meta-analysis confirmed that TVT surgery and pelvic floor repair surgery can significantly improve the clinical cure rate of female patients with pelvic organ prolapse 
combined with SUI, and the incidence of complications is low. Therefore, for female patients with pelvic organ prolapse combined with SUI, TVT surgery is a highly safe and effective surgical method. In conclusion, the results of this study can provide a reference for the surgical treatment of female patients with pelvic organ prolapse combined with SUI.

\section{Acknowledgments}

Funding: None.

\section{Footnote}

Reporting Checklist: The authors have completed the PRISMA reporting checklist. Available at https://dx.doi. org/10.21037/apm-21-3385

Conflicts of Interest: All authors have completed the ICMJE uniform disclosure form (available at https://dx.doi. org/10.21037/apm-21-3385). The authors have no conflicts of interest to declare.

Ethical Statement: The authors are accountable for all aspects of the work in ensuring that questions related to the accuracy or integrity of any part of the work are appropriately investigated and resolved.

Open Access Statement: This is an Open Access article distributed in accordance with the Creative Commons Attribution-NonCommercial-NoDerivs 4.0 International License (CC BY-NC-ND 4.0), which permits the noncommercial replication and distribution of the article with the strict proviso that no changes or edits are made and the original work is properly cited (including links to both the formal publication through the relevant DOI and the license). See: https://creativecommons.org/licenses/by-nc-nd/4.0/.

\section{References}

1. Capobianco G, Madonia M, Morelli S, et al. Management of female stress urinary incontinence: A care pathway and update. Maturitas 2018;109:32-8.

2. Zugor V, Akbarov I, Karapanos L, et al. Surgical management of female stress urinary incontinence. Aktuelle Urol 2018;49:78-82.

3. Bauer RM, Ameli G, Schultz-Lampel D, et al. Stress urinary incontinence in men. Urologe A 2021;60:109-18.
4. Padilla-Fernández B, Ramírez-Castillo GM, HernándezHernández D, et al. Urodynamics Before Stress Urinary Incontinence Surgery in Modern Functional Urology. Eur Urol Focus 2019;5:319-21.

5. Blaivas JG, Simma-Chiang V, Gul Z, et al. Surgery for Stress Urinary Incontinence: Autologous Fascial Sling. Urol Clin North Am 2019;46:41-52.

6. Bernardes BT, Resende AP, Stüpp L, et al. Efficacy of pelvic floor muscle training and hypopressive exercises for treating pelvic organ prolapse in women: randomized controlled trial. Sao Paulo Med J 2012;130:5-9.

7. Duarte TB, Bø K, Brito LGO, et al. Perioperative pelvic floor muscle training did not improve outcomes in women undergoing pelvic organ prolapse surgery: a randomised trial. J Physiother 2020;66:27-32.

8. Zhang FW, Wei F, Wang HL, et al. Does pelvic floor muscle training augment the effect of surgery in women with pelvic organ prolapse? A systematic review of randomized controlled trials. Neurourol Urodyn 2016;35:666-74.

9. Bø K. Pelvic floor muscle training in treatment of female stress urinary incontinence, pelvic organ prolapse and sexual dysfunction. World J Urol 2012;30:437-43.

10. Resende APM, Bernardes BT, Stüpp L, et al. Pelvic floor muscle training is better than hypopressive exercises in pelvic organ prolapse treatment: An assessor-blinded randomized controlled trial. Neurourol Urodyn 2019;38:171-9.

11. Good MM, Solomon ER. Pelvic Floor Disorders. Obstet Gynecol Clin North Am 2019;46:527-40.

12. Braekken IH, Majida M, Engh ME, et al. Can pelvic floor muscle training reverse pelvic organ prolapse and reduce prolapse symptoms? An assessor-blinded, randomized, controlled trial. Am J Obstet Gynecol 2010;203:170.e1-7.

13. Borstad E, Abdelnoor M, Staff AC, et al. Surgical strategies for women with pelvic organ prolapse and urinary stress incontinence. Int Urogynecol J 2010;21:179-86.

14. Brubaker L, Nager CW, Richter HE, et al. Effectiveness of blinding: sham suprapubic incisions in a randomized trial of retropubic midurethral sling in women undergoing vaginal prolapse surgery. Am J Obstet Gynecol 2014;211:554.e1-7.

15. Costantini E, Zucchi A, Giannantoni A, et al. Must colposuspension be associated with sacropexy to prevent postoperative urinary incontinence? Eur Urol 2007;51:788-94.

16. Costantini E, Lazzeri M, Bini V, et al. Burch colposuspension does not provide any additional 
benefit to pelvic organ prolapse repair in patients with urinary incontinence: a randomized surgical trial. J Urol 2008;180:1007-12.

17. Holdø B, Verelst M, Svenningsen R, et al. Longterm clinical outcomes with the retropubic tensionfree vaginal tape (TVT) procedure compared to Burch colposuspension for correcting stress urinary incontinence (SUI). Int Urogynecol J 2017;28:1739-46.

18. Meschia M, Pifarotti P, Bernasconi F, et al. Tension-free vaginal tape (TVT) and intravaginal slingplasty (IVS) for stress urinary incontinence: a multicenter randomized trial. Am J Obstet Gynecol 2006;195:1338-42.

19. Montera R, Scaletta G, Plotti F, et al. The role of macroplastique implantation in the management of occult urinary stress incontinence. Eur J Obstet Gynecol Reprod Biol 2018;225:124-8.

20. de Tayrac R, Gervaise A, Chauveaud-Lambling A, et al. Combined genital prolapse repair reinforced with a polypropylene mesh and tension-free vaginal tape in women with genital prolapse and stress urinary incontinence: a retrospective case-control study with short-term follow-up. Acta Obstet Gynecol Scand 2004;83:950-4.

21. Sokol AI, Jelovsek JE, Walters MD, et al. Incidence and predictors of prolonged urinary retention after TVT with and without concurrent prolapse surgery. Am J Obstet Gynecol 2005;192:1537-43.

22. Takahashi S, Obinata D, Sakuma T, et al. Transvaginal mesh (TVM) reconstruction with TVT/TOT sling for vaginal prolapse concurrent with stress urinary incontinence. Aktuelle Urol 2010;41 Suppl 1:S20-3.

23. Wu YM, Welk B. Revisiting current treatment options

Cite this article as: He P, Zou J, Gong B, Qiu M, Li L. Systematic review and meta-analysis of the efficacy of tensionfree vaginal tape on pelvic organ prolapse complicated by stress urinary incontinence. Ann Palliat Med 2021;10(12):12589-12597. doi: 10.21037/apm-21-3385 for stress urinary incontinence and pelvic organ prolapse: a contemporary literature review. Res Rep Urol 2019;11:179-88.

24. Colaco M, Mettu J, Badlani G. The scientific basis for the use of biomaterials in stress urinary incontinence (SUI) and pelvic organ prolapse (POP). BJU Int 2015;115:859-66.

25. Wang SM, Zhang ZY, Liu CD, et al. Study on concomitant surgical correction of pelvic organ prolapse and TVT-O for treatment of stress urinary incontinence. Zhonghua Fu Chan Ke Za Zhi 2013;48:494-8.

26. Serati M, Braga A, Caccia G, et al. TVT-O for treatment of pure urodynamic stress urinary incontinence: Efficacy and adverse effects at 13-years follow-up. Neurourol Urodyn 2020;39:1423-9.

27. Bakas P, Papadakis E, Karachalios C, et al. Assessment of the long-term outcome of TVT procedure for stress urinary incontinence in a female population: results at 17 years' follow-up. Int Urogynecol J 2019;30:265-9.

28. Yang X, Jiang M, Chen X, et al. TVT-O vs. TVT for the treatment of SUI: a non-inferiority study. Int Urogynecol J 2012;23:99-104.

29. Song B, He Y, Shen R, et al. TVT-O vs TVT-S for female stress urinary incontinence: A systematic review and metaanalysis. Int J Clin Pract 2020;74:e13506.

30. Rodrigues CA, Bianchi-Ferraro AMHM, Zucchi EVM, et al. Pelvic Floor 3D Ultrasound of Women with a TVT, TV'T-O, or TVT-S for Stress Urinary Incontinence at the Three-year Follow-up. Rev Bras Ginecol Obstet 2017;39:471-9.

(English Language Editor: A. Kassem) 